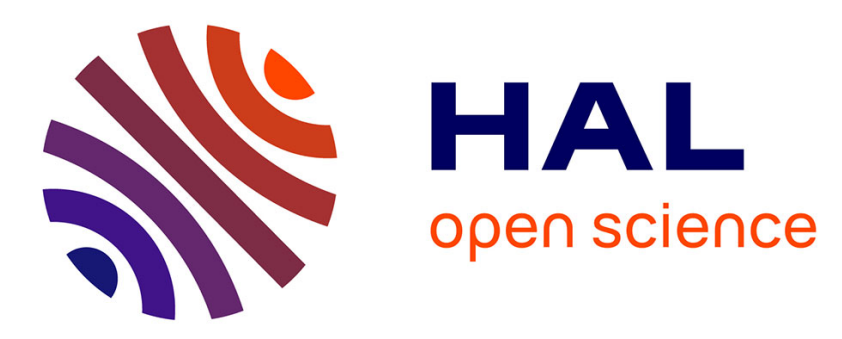

\title{
Nonlinear Mechanism in MEMS Devices for Energy Harvesting Applications
}

Carlo Trigona, Bruno Ando, Salvatore Baglio, Pascal Nouet, Laurent Latorre, Norbert Dumas

\section{- To cite this version:}

Carlo Trigona, Bruno Ando, Salvatore Baglio, Pascal Nouet, Laurent Latorre, et al.. Nonlinear Mechanism in MEMS Devices for Energy Harvesting Applications. Journal of Micromechanics and Microengineering, 2010, 20 (12), pp.1-12. 10.1088/0960-1317/20/12/125020 . lirmm-00555283

\section{HAL Id: lirmm-00555283 https://hal-lirmm.ccsd.cnrs.fr/lirmm-00555283}

Submitted on 12 Jan 2011

HAL is a multi-disciplinary open access archive for the deposit and dissemination of scientific research documents, whether they are published or not. The documents may come from teaching and research institutions in France or abroad, or from public or private research centers.
L'archive ouverte pluridisciplinaire HAL, est destinée au dépôt et à la diffusion de documents scientifiques de niveau recherche, publiés ou non, émanant des établissements d'enseignement et de recherche français ou étrangers, des laboratoires publics ou privés. 
Nonlinear mechanism in MEMS devices for energy harvesting applications

This article has been downloaded from IOPscience. Please scroll down to see the full text article.

2010 J. Micromech. Microeng. 20125020

(http://iopscience.iop.org/0960-1317/20/12/125020)

View the table of contents for this issue, or go to the journal homepage for more

Download details:

IP Address: 194.254.112.129

The article was downloaded on 19/11/2010 at 10:43

Please note that terms and conditions apply. 


\title{
Nonlinear mechanism in MEMS devices for energy harvesting applications
}

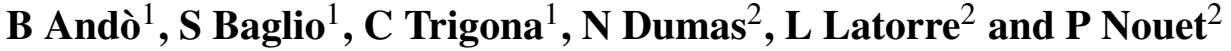 \\ ${ }^{1}$ D.I.E.E.S., University of Catania, Catania, Italy \\ ${ }^{2}$ L.I.R.M.M., University Montpellier II, Montpellier, France \\ E-mail: carlo.trigona@diees.unict.it
}

Received 6 August 2010, in final form 7 October 2010

Published 18 November 2010

Online at stacks.iop.org/JMM/20/125020

\begin{abstract}
This paper reports a novel bistable microelectromechanical system for energy harvesting applications. In particular, we focus here on methodologies and devices for recovering energy from mechanical vibrations. A common energy harvesting approach is based on vibrating mechanical bodies that collect energy through the adoption of self-generating materials. This family of systems has a linear mass-spring damping behaviour and shows good performance around its natural frequency. However, it is not generally suitable for energy recovery in a wide spectrum of frequencies as expected in the vast majority of cases when ambient vibrations assume different forms and the energy is distributed over a wide range of frequencies.

Furthermore, whenever the vibrations have a low frequency content the implementation of an integrated energy harvesting device is challenging; in fact large masses and devices would be needed to obtain resonances at low frequencies. Here, the idea is to consider the nonlinear behaviour of a bistable system to enhance device performances in terms of response to external vibrations. The switching mechanism is based on a structure that oscillates around one of the two stable states when the stimulus is not large enough to switch to the other stable state and that moves around the other stable state as soon as it is excited over the threshold. A response improvement can be demonstrated compared to the classical linear approach. Indeed, both a wider spectrum will appear as a consequence of the nonlinear term and a significant amount of energy is collected at low frequencies. In this paper the bistable working principle is first described and analytically modelled, and then a numerical study based on stochastic differential equations (SDE) is realized to evaluate the behaviour of a MEMS device. A micromachined SOI prototype has been realized and a measurement campaign validated the nonlinear mechanism. As expected, the study shows that the nonlinear system exhibits a low pass filter behaviour suitable for harvesting ambient energy at low frequency.
\end{abstract}

(Some figures in this article are in colour only in the electronic version)

\section{Introduction}

Energy harvesting materials and systems have emerged as a prominent research area and continue to grow at a rapid pace. A wide range of applications are targeted for harvesters, including embedded and implanted sensor nodes [1], refilling the batteries of large systems [2], self-powered sensors [3], powering unmanned vehicles [4], human-powered energy harvesting [5] and smart systems [6]. The most common sources for ambient energy are solar power, thermal gradients, acoustic and mechanical vibrations. In particular the latter usually offers a significant amount of energy and it is a potential power source that is abundant enough to be used; moreover, it is extremely interesting in view of applications based on MEMS technology where different renewable power sources can be combined into autonomous integrated devices.

Vibration energy can be converted into electrical power through piezoelectric materials (e.g. PZT), electromagnetic and electrostatic transducers. Most vibration energy harvesters are based on a mechanically resonant device that collect a narrow band of vibrations, hopefully matched with the source. 
However, in the vast majority of cases the ambient mechanical vibrations come in a vast variety of forms (induced oscillations, seismic noise, vehicle motion, thermal noise, multi-tone vibrating system and more generally, all noisy environments and equipments). Energy is then distributed over a wide spectrum of frequencies, typically ranging from dc up to a few thousands of $\mathrm{Hz}$ [7]. Several methods for optimization have been explored, relating to increasing the converted and extracted energies or improving the transduction mechanisms. Recently, a resonance frequency tunable energy harvester based on a magnetic force technique and a variable beam stiffness system $[8,9]$ has been proposed in order to obtain a wide spectrum response and to adapt the harvester to the vibration source. Moreover, an approach based on a PZT multi-frequency converter array has been recently studied [10]; it combines multiple linear converters with different frequency responses to obtain a wider equivalent bandwidth. A similar approach based on the electromagnetic principle is presented in [11], where power is generated by means of electromagnetic induction using a magnet and serially connected coils placed on resonating multi-length cantilever beams. In addition, methods to obtain mechanical frequency upconversion are being investigated. Other novel approaches have been presented in the literature; the common point is to increase the energy recovery capability of the system. An energy harvester based on a magnetic levitation principle [12] has been designed to tune the resonance frequency of the oscillator; furthermore, another example is given in [13], where a frequency upconversion in a PZT bimorph cantilever has been proposed. In [14], the authors present the use of magnetic arrays to rectify the incoming frequency to a higher frequency combined with energy conversion via the piezoelectric effect. In [15], an energy harvester that combines PZT and magnetic materials with a tuning system in order to be able to react to small and slow variations of temperature has been proposed. In [16], the authors analytically studied the power-benefit of an additive periodic force to a vibrationally excited energy harvesting mechanism, exploiting the stochastic resonance theory.

A different approach is presented here: it is based on the exploitation of the properties of 'nonresonant' oscillators characterized by a nonlinear dynamic response. For these oscillators, it is not possible to define a transfer function, and thus a properly defined resonant frequency, even if the power spectral density can show one or more well-defined peaks. Furthermore, a wider spectrum is predicted [17, 18] for a nonlinear system with respect to the linear oscillator; this represents an interesting result in the perspective of a single harvester system. Several works have been presented in the literature concerning nonlinear macro-oscillators based on bistable dynamics. For example in [17] the authors present a nonlinear energy harvester based on magnetic interactions in order to create an inertial generator with a bistable potential energy function; instead in [19] a nonlinear vibration energy harvester has been used to improve the operative range considering also a chaotic motion. A scaling approach has been proposed such as presented in [20], where a compliant bistable mechanism driven by electromagnetic force has been validated.
In this paper, a MEMS tunable bistable oscillator for energy harvesting application will be presented. The principle has been previously demonstrated on macro cantilever prototypes and millimetre scale [21-24], while this work describes downscaling to a microscale. Numerical analyses have been conducted by using a nonlinear stochastic solver for differential equations implementing a nonlinear oscillator equation. The Itô's stochastic calculus has been used to solve the MEMS model by using a stochastic process in order to emulate external vibrations. The goal of this study has been to relate external noisy vibrations to device displacement and device velocity. In fact, these latter quantities will be crucial in the mechanical-to-electrical conversion step; therefore whatever the final mechanism used for producing electrical energy, higher magnitudes for displacement and velocity will result in higher power. A bistable BESOIMEMS (back etched SOI) device has been fabricated and an experimental campaign has been realized. The results are in accordance with the mathematical model of the system, thus demonstrating suitability of the proposed novel approach.

\section{Device modelling}

Most vibration harvesters are based on linear oscillating devices that provide the maximum efficiency when operated at resonance [10]. The resonance condition in vibration bandwidth $(<1 \mathrm{kHz}$ [7]) is difficult to match with the microscale dimensions of the converter, and it is hard to maintain when the excitation is not controllable or when vibration frequency moves over a broad bandwidth. This is counterproductive in terms of harvester efficiency.

The approach that will be pursued in this work is based on the exploitation of the dynamic properties of nonlinear oscillators, in particular bistable systems [21, 22]. Especially, we demonstrate that a MEMS bistable oscillator [25] in the presence of an optimal level of noise can provide better performances compared to a linear oscillator when vibrations range over a wide spectrum of frequencies.

Several research papers have reported successful realization of bistable mechanical devices [26-28] where the switching between both stable states is driven by internal signals and statically verified. Figure 1 shows the nonlinear mechanism implemented here. The bistable principle has been realized using a cantilever beam with a permanent magnet deposited onto the top surface. A fixed magnet has been placed in front of the cantilever tip at a distance $\Delta$, under a repulsive magnetic force condition. The linear case can be assumed for a large distance between both magnets. Furthermore, the nonlinear case is assumed when low distance between magnets occurs. The fixed magnet generates a force dependent on $\Delta$ that opposes the elastic reaction force of the beam. Under the action of the external vibrations, the system oscillates.

As a result, the system can assume two different dynamics.

- When the magnetic repulsive force is negligible (large value of $\Delta$ ), the system behaviour can be assumed to be a linear oscillator, so a resonance response is expected and a second-order model with parabolic potential energy function can be assumed. 

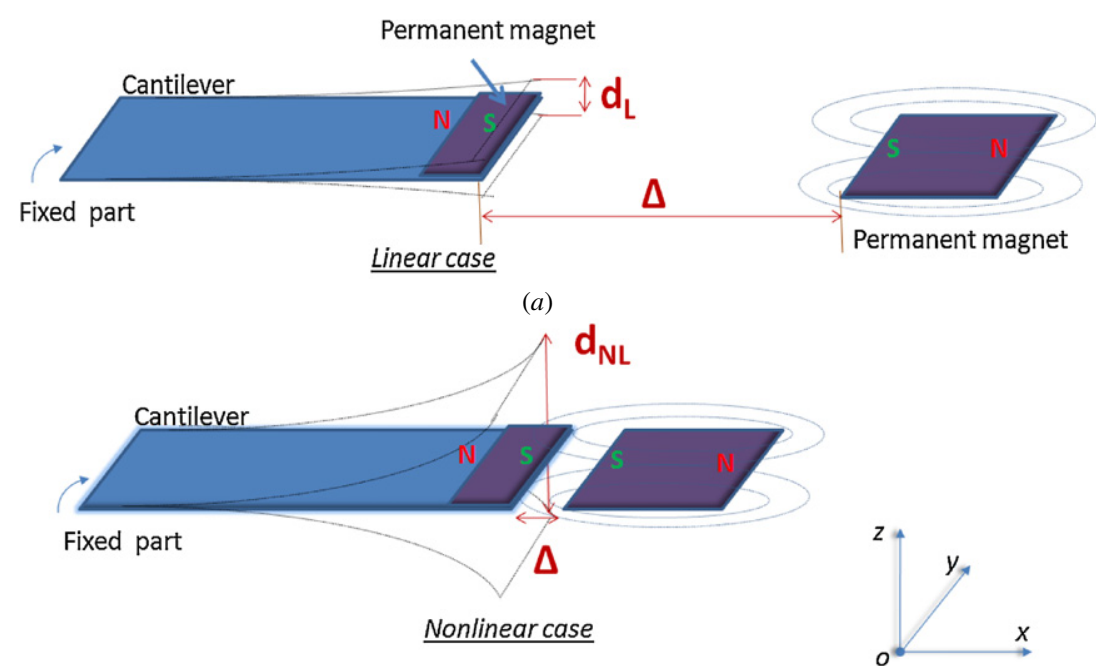

(b)

Figure 1. Cantilever beam (a) immune to magnetic repulsive force, therefore linear and $(b)$ subject to magnetic repulsive force; $d_{L}$ and $d_{\mathrm{NL}}$ represent the displacement of the beam in the linear and nonlinear cases, respectively.

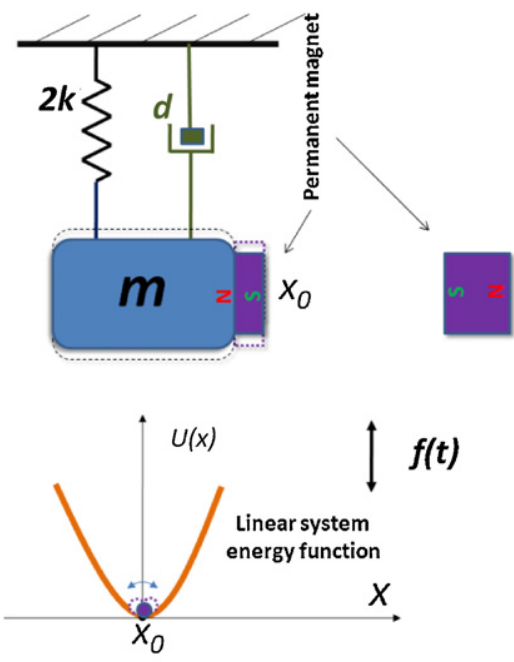

(a)

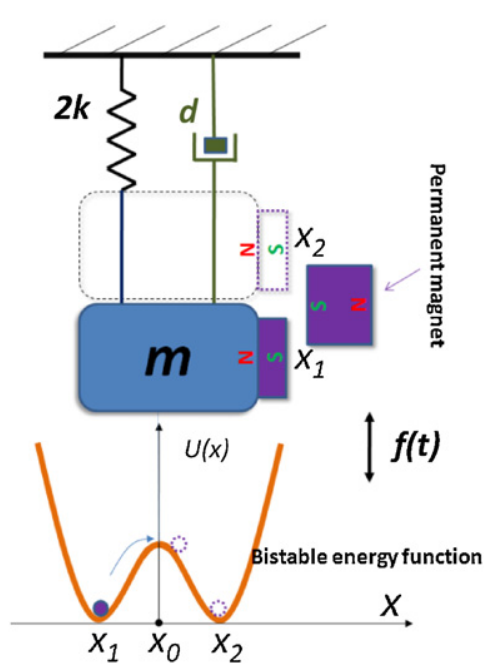

(b)

Figure 2. (a) High value of $\Delta$ (distance between the two magnets). The system can be assumed to be linear and the parabolic function describes the energy. (b) Small value of $\Delta$, a bistable energy function appears and dictates the system dynamic. Two equilibrium states $x_{1}$ and $x_{2}$ will appear, while $x_{0}$ represents the instable condition. In the linear case only a stable state exists $\left(x_{0}\right)$.

- When the fixed permanent magnet is close to the tip of the beam (small value of $\Delta$ ), the behaviour can be described by a nonlinear model. In fact new equilibrium positions appear, so a bistable potential energy function imposes the dynamic.

The latter case raises high interest; indeed it is then possible to use the wider bandwidth (dictated by the nonlinear energy function) to collect more energy from the ambient vibrations.

The wide spectrum response is a feature of several nonlinear systems (bistable, multi stable, etc) whereas linear systems do not exhibit high yields in applications where a large spectrum is required (e.g. vibrations, white noise, random sources, etc). The nonlinear system has been modelled considering a classical mass-spring damper system with an additive nonlinear term described by a bistable (double well) potential energy function:

$$
m \ddot{x}+d \dot{x}+\Psi=f(t),
$$

where $m$ represents the mass of the cantilever beam, $d$ is the damping coefficient and $f(t)$ is the stochastic source, in order to mimic the external vibrations to be harvested; $x$ represents the displacement of the cantilever. The velocity and the acceleration have been expressed as $\dot{x}\left(\frac{\partial x}{\partial t}\right)$ and $\ddot{x}\left(\frac{\partial^{2} x}{\partial t^{2}}\right)$, respectively. $\Psi$ represents the nonlinear term, consequence of the bistable behaviour, and includes the elastic constant term $k$ (figure 2) as will be expressed in equation 3 [29]:

$$
\Psi \triangleq \frac{\partial U(x)}{\partial x}=U(x)
$$

Different types of bistable potentials can typically be used $[30,31]$. 


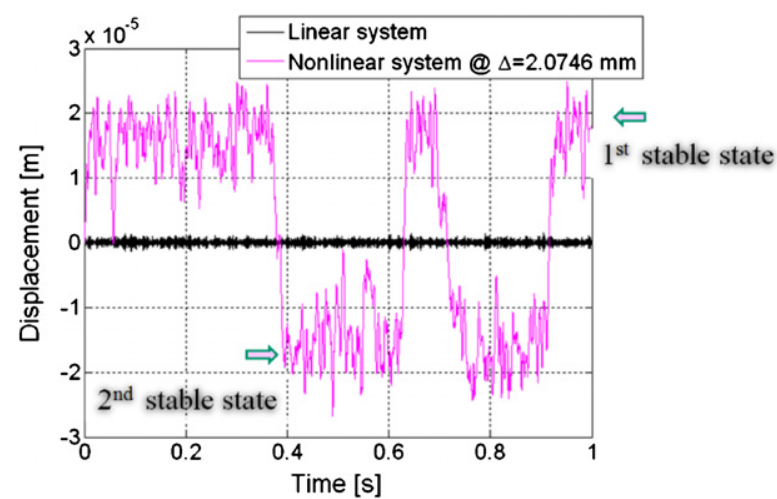

(a)

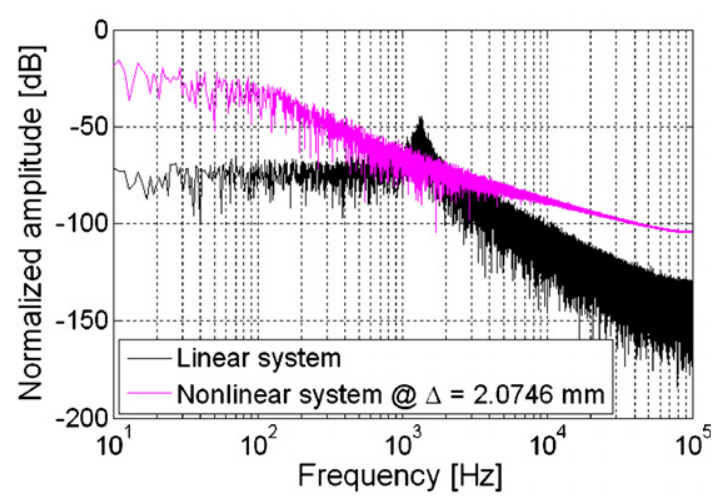

(b)

Figure 3. (a) Displacement of the cantilever beam in the linear case and under the optimal condition for the nonlinear system at $\sigma=50 \mathrm{mN}$, (b) displacement spectrum. The simulation parameters are the following: $k=70000 \mathrm{~kg} \mathrm{~s}^{-2}, d=1 \mathrm{~kg} \mathrm{~s}^{-1}, m=0.001 \mathrm{~kg}$.

(1) Standard quadratic equation: $U(x)=-\alpha x^{2}+\beta x^{4}$, with stable fixed points at $x= \pm\left(\frac{\alpha}{2 \beta}\right)^{\frac{1}{2}}$ and the barrier of the potential is $U_{0}=\frac{\alpha^{2}}{4 \beta}$, and $x$ denotes the distance parameter of potential energy function. The two parameters $\alpha$ and $\beta$ determine the potential shape (bistable or monostable).

(2) Analog Hopfield neuron: $U(x)=\alpha x^{2}-\beta \ln \cosh (x)$, where $x(t)$ denotes a cell membrane voltage. The same nonlinearity has been used by the authors [32] to describe the behaviour of residence time difference of fluxgate magnetometers.

(3) Rf squid loop: $U(x)=\alpha x^{2} \beta \cos (2 \pi x)$, where $x(t)$ denotes the magnetic flux in the loop.

The choice of the potential $U(x)$ among various possible expressions is closely related to the considered physical system and to the particular mechanism assumed. The model of the system has been assumed as a nonlinear pendulum governed by a double well nonlinearity [21]. Hence the potential energy function correlated to the oscillator is as follows:

$$
U(x)=k x^{2}+\left(a x^{2}+b \Delta^{2}\right)^{-\frac{3}{2}}+c \Delta^{2} .
$$

Taking into account the expression of $\Psi$ :

$$
\begin{aligned}
\Psi & =U(x)=\frac{\partial}{\partial x}\left[k x^{2}+\left(a x^{2}+b \Delta^{2}\right)^{-\frac{3}{2}}+c \Delta^{2}\right] \\
& =2 k x+\left[\frac{-\frac{3}{2}\left(a x^{2}+b \Delta^{2}\right)^{\frac{1}{2}} 2 a x}{\left(a x^{2}+b \Delta^{2}\right)^{3}}\right] \\
& =-3 a x\left(a x^{2}+b \Delta^{2}\right)^{-\frac{5}{2}}+2 k x,
\end{aligned}
$$

where $x$ represents the displacement of the cantilever beam, $k$ the elastic constant, $\Delta$ is the distance between the two magnets (the first deposited onto the cantilever surface and the second in the external part of the system and maintained fixed) and $a, b$ and $c$ represent constants correlated to the physical parameters of the systems [21].

The model is represented by a stochastic differential equation, which can be expressed in Itô's form [33] that represents a standard nomenclature used to study a dynamic system with stochastic forcing. The beam model can be expressed as follows:

$$
d x=f(x) d t+g(x) d W_{t},
$$

where $f(x)$ represents the drift part of the Itô's model, $g(x)$ is the diffusion term and $W_{t}$ the Wiener process. The stochastic differential equations that describe the bistable mechanism have been implemented through a mathematical system:

$$
\left\{\begin{aligned}
d x_{1}= & x_{2} d t=f_{1}(x) d t \\
d x_{2}= & {\left[-\frac{d}{m} x_{2}+\frac{3 a x_{1}\left(a x_{1}^{2}+b \Delta^{2}\right)^{-\frac{5}{2}}}{m}\right.} \\
& \left.-\frac{2 k x_{1}}{m}\right] d t+\frac{\sigma}{m} d W_{t} \\
= & f_{2}(x) d t+g_{2}(x) d W_{t} .
\end{aligned}\right.
$$

The system of equations is composed of two first-order Itô's equations with two drift terms: (1) $f_{1}(x)$ represents the velocity $\left(x_{2}\right)$ of the cantilever tip and (2) $f_{2}(x)$ depends on the damping, the elastic constant and a nonlinear term.

$g_{2}(x)$ represents the diffusion term, it is function of the vibration amplitude $(\sigma)$ and is also correlated to the mass of the system; $x_{1}$ is the displacement of the beam and $t$ is the time.

The diffusion term $g_{1}(x)$ has been assumed to be zero, indeed the system is excited by a single source, so only one diffusion term is included in the model.

In the following section a numerical study based on the SDE Toolbox of Matlab ${ }^{\circledR}$ [34] will be presented in order to simulate the behaviour of a millimetre system and afterwards to evaluate the scaling effect applied to a micromachined device. In fact the validity of the model in a micrometric scale is prominent in the perspective of a MEMS energy harvester realization.

\section{Numerical analysis of the nonlinear MEMS mechanism}

Itô SDE equations have been implemented adopting the SDE toolbox of Matlab ${ }^{\circledR}$. A first analysis has been applied to a millimetre system: a cantilever beam having a length of $20 \mathrm{~mm}$, a width of $4 \mathrm{~mm}$ and a thickness of $2 \mathrm{~mm}$. A homogeneous beam material (aluminium) has been assumed. The mass of the system corresponds to $1 \mathrm{~g}$. The EulerMaruyama method has been used to evaluate the dynamic behaviour [35]. Figure 3 shows the displacement of the 


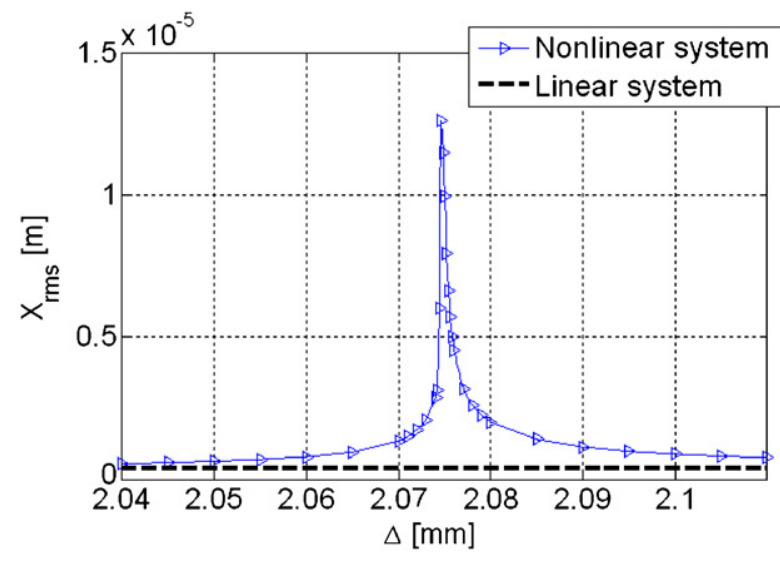

(a)
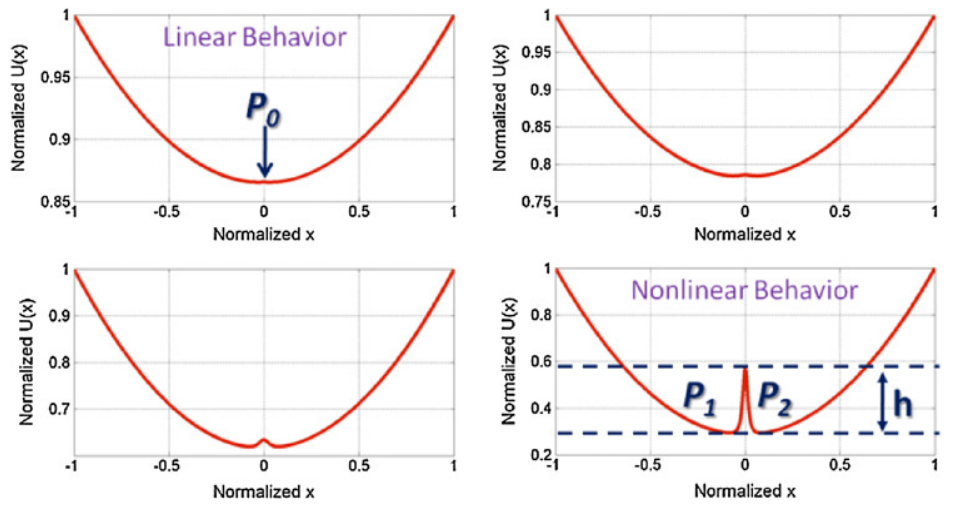

(b)

Figure 4. (a) Root mean square of the displacement; the spike denotes the optimal condition for the bistable system; the linear behaviour has been obtained through a simulation in the absence of the external permanent magnet. The value tends to be equal to the displacement assuming a high value of $\Delta$. (b) Qualitative analysis of the potential energy function shape tuning the distance $\Delta ; h$ denotes the barrier of potential. Typically the optimal condition in terms of bandwidth is assumed for small values of $h$.

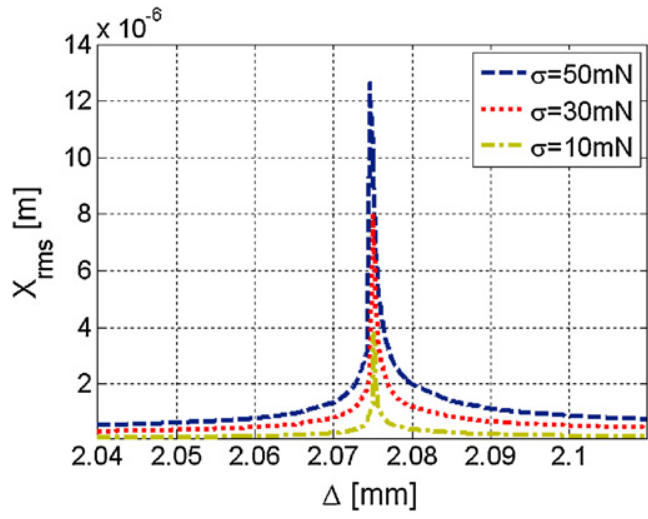

(a)

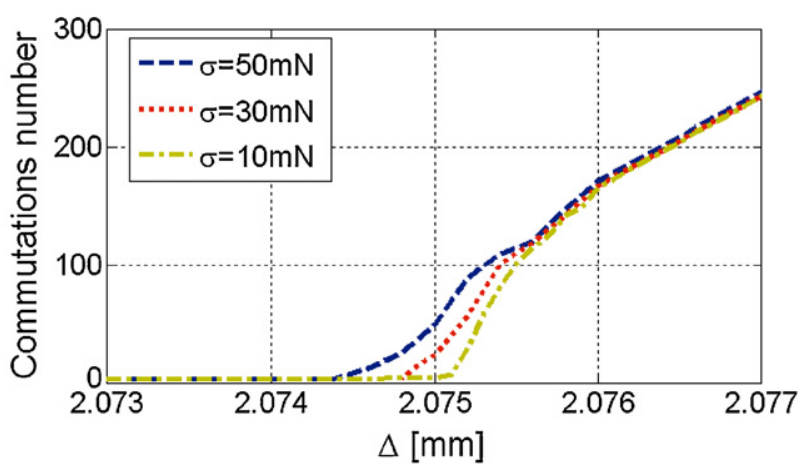

(b)

Figure 5. (a) Root mean square of the displacement and $(b)$ commutations number versus distance between the two permanent magnets for three different values of standard deviation. The system numerically simulated consists in a cantilever beam realized in a millimetre scale.

cantilever beam in the linear case (absence of the external permanent magnet) and in the nonlinear case (distance of $2.0746 \mathrm{~mm}$ between the two magnets), respectively; moreover, the output evinces a wider spectrum when the energy function assumes a bistable shape, so more energy can be saved adopting a bistable dynamic. Simulations have been realized considering a vibration source (Gaussian white noise) having a standard deviation $(\sigma)$ of $50 \mathrm{mN}$. As shown in figure 4(a), a maximum value of the displacement tip exists for $\Delta \sim 2.0746 \mathrm{~mm}$, which corresponds to the peak condition. The graph shows the ac part of the signal. Taking smaller values of $\Delta$ implies higher interactions between the two permanent magnets, high potential energy barrier and, consequently, oscillations inside a single well of the potential energy function. Furthermore, a high distance $\Delta$ between the two permanent magnets implies a zero barrier of energy with a parabolic energy function as shown in figure $4(b) . \mathrm{P}_{1}$ and $\mathrm{P}_{2}$ represent the two stable states. The transition between one stable state and the other one occurs only when vibration level is high enough to pass from $\mathrm{P}_{1}$ to $\mathrm{P}_{2}$ and vice versa.

The behaviour has been analysed considering different amplitudes of vibrations. Figure 5(a) shows the root-mean- square (rms) value of the displacement as a function of $\Delta$; as a consequence of the amplitude source decrement a more selective tuning of $\Delta$ is required. Figure $5(b)$ shows the number of transition around the zero for different amplitudes of a noise source $(\sigma=10,30,50 \mathrm{mN})$; lower amplitudes of excitation are counterbalanced by a sharp switching between the linear and the bistable condition increasing the selectivity of tuning. Small amplitude of vibration and compactness of the structure are important characteristics especially in the perspective of a MEMS device. For this reason a downscaling of the system has been considered and the validation of the model will be demonstrated. Different kinds of MEMS cantilever beam have been studied and different technologies pursued; here a cantilever beam based on a SOI substrate is reported. Simulations have been realized using the same solver as for the previous analysis and implementing the stochastic differential equation (6). Figure 6(a) shows the results for a micromachined cantilever based on MEMS technology; a silicon-on-insulator (SOI) beam having a length of $2000 \mu \mathrm{m}$ and a width of $800 \mu \mathrm{m}$ has been studied. The results are in accordance with the cantilever beam of a millimetre scale previously simulated; two values of $\sigma$ have been accounted 


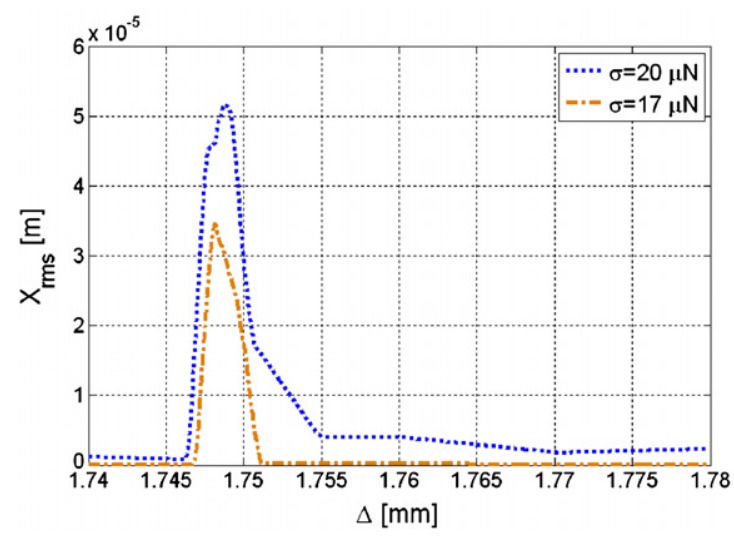

(a)

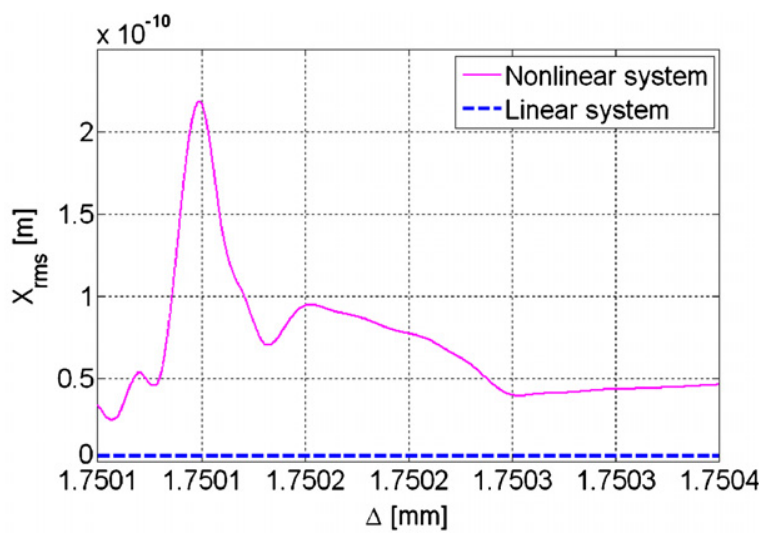

(b)

Figure 6. Root mean square of the displacement (a) for two different values of $\sigma(17$ and $20 \mu \mathrm{N})$ and $(b)$ for a railroad vibration source ( $40 \mathrm{pN}$ distributed over a bandwidth of $2 \mathrm{MHz}$ ).

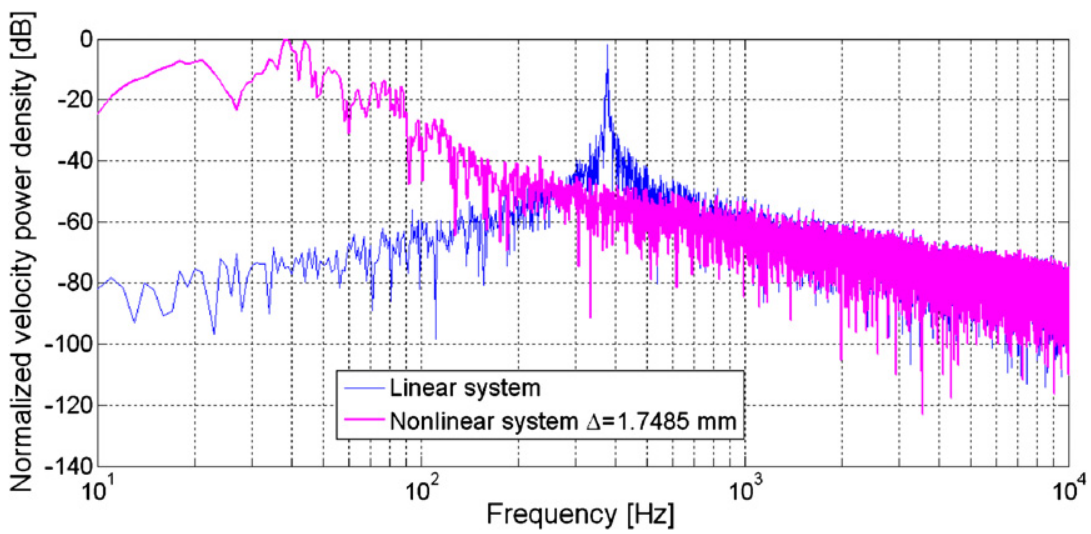

Figure 7. Velocity power spectral density. The value $\Delta=1.7485 \mathrm{~mm}$ corresponds to the optimal repulsive force in terms of maximum velocity of the nonlinear system $(\sigma=20 \mu \mathrm{N})$.

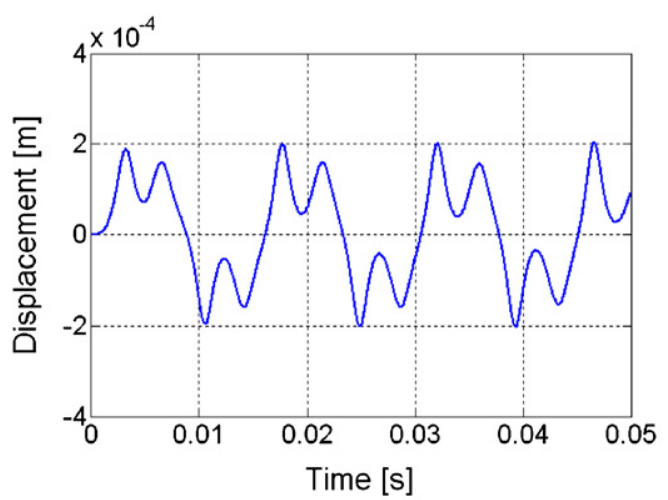

(a)

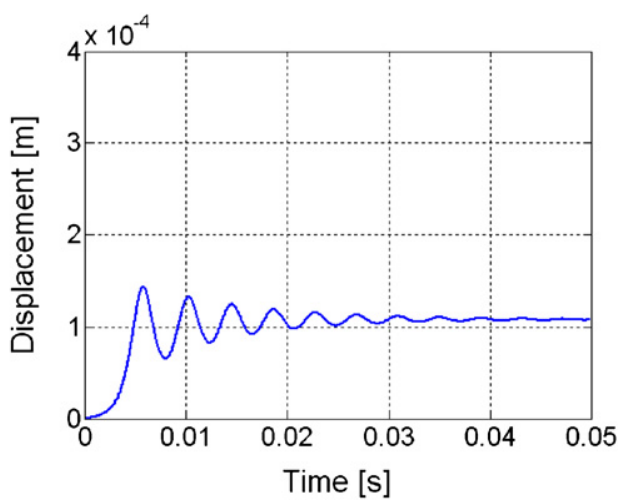

(b)

Figure 8. Single tone analysis of a MEMS cantilever based on SOI technology: (a) displacement of the beam excited by a sinusoidal waveform with an amplitude magnitude of $17 \mu \mathrm{N}$ (rms value) at $70 \mathrm{~Hz}$ and $(b)$ at $7 \mathrm{kHz}$.

for $(17$ and $20 \mu \mathrm{N})$. Moreover, a noise source with a standard deviation of $40 \mathrm{pN}$ has been considered in order to mimic a railroad vibration (figure 6(b)) [36].

Figure 7 shows the PSD of velocity, from the perspective of a PZT material deposition, where the harvested performance is correlated to the oscillator commutation velocity; a spring constant of $15 \mathrm{~kg} \mathrm{~s}^{-2}$ and an inertial mass of $2.6 \times 10^{-6} \mathrm{~kg}$ have been considered. In the linear case the power is mostly collected around the natural resonance of the moving part, whereas in the nonlinear case the power is efficiently collected from 0 up to $100 \mathrm{~Hz}$. This clearly shows that the nonlinear system is more suitable for typical noisy environment where energy is scattered below few hundred of Hz. Finally, the micromachined device has been simulated using a DormandPrince ODE 45 (ordinary differential equation) solver of Matlab ${ }^{\circledR}$ and driven by a sinusoidal force. Figure $8(a)$ shows 


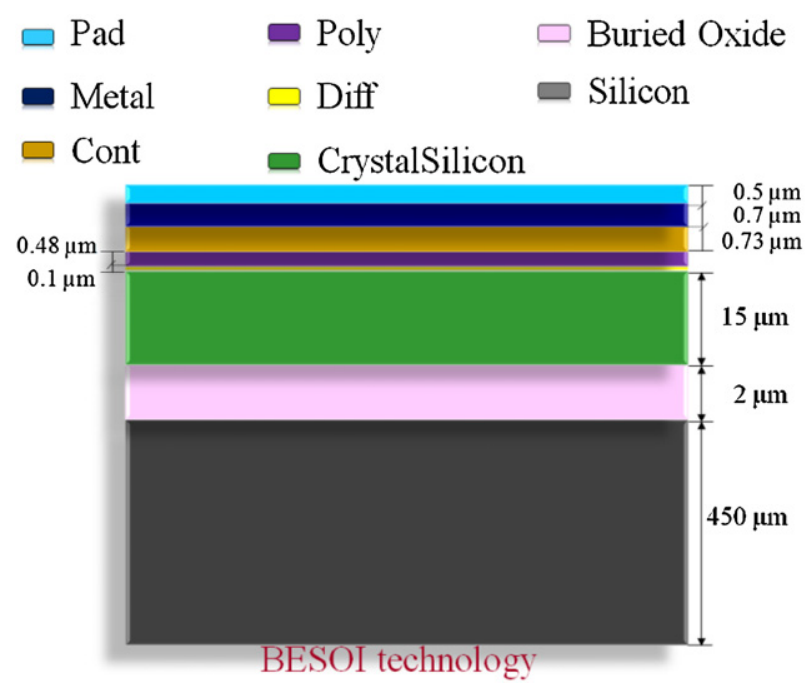

(a)

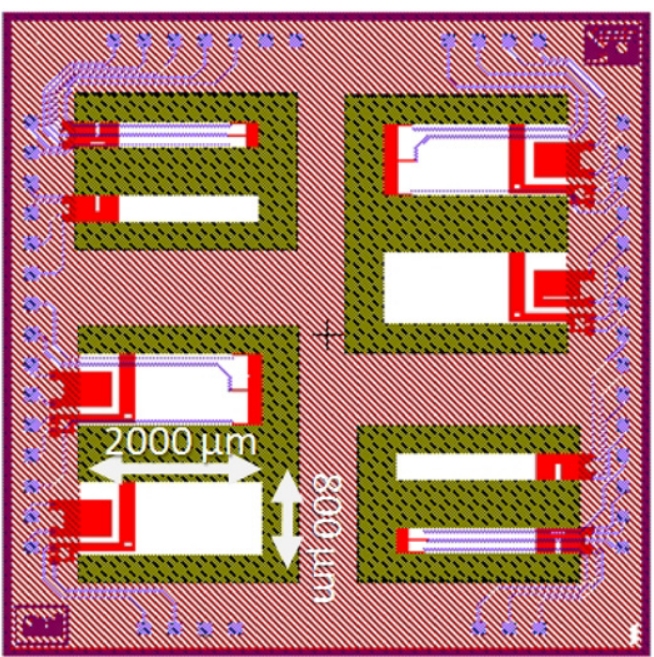

(b)

Figure 9. (a) Bulk and etched silicon on insulator (BESOI) technology selected as the realization process of the nonlinear oscillator, (b) layout of the cantilever beam and other structures used as test. The die size is $7 \mathrm{~mm} \times 7 \mathrm{~mm}$.

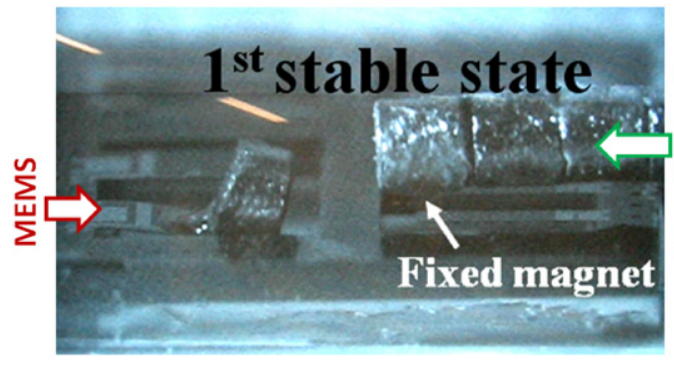

(a)

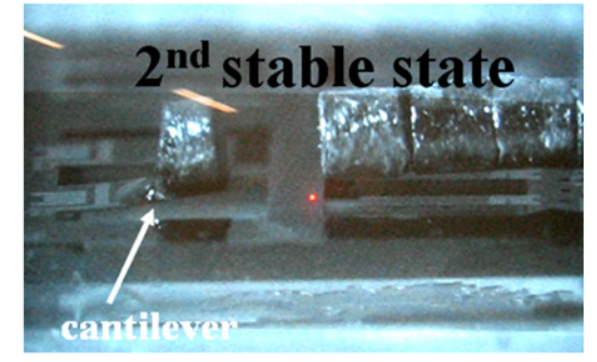

(b)

Figure 10. Microscope image of the MEMS cantilever with the permanent magnet deposited at the tip; in front, the tunable magnetic stack: (a) first stable state, $(b)$ second stable state.

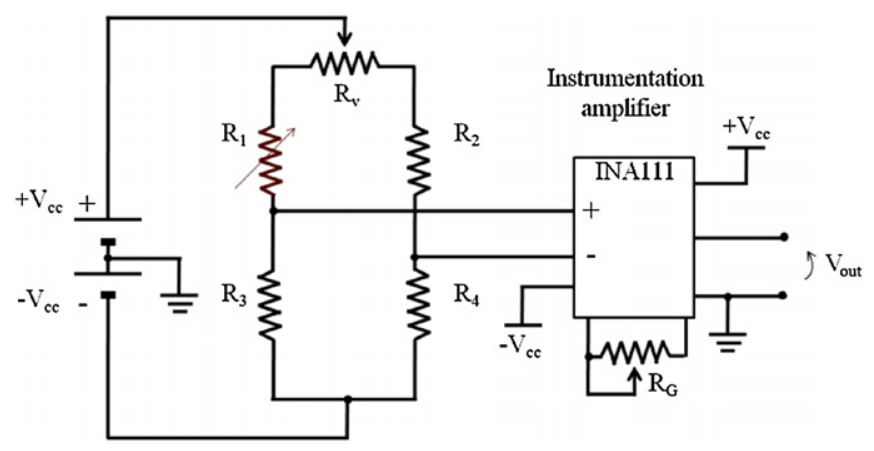

Figure 11. Conditioning circuit: $R_{v}$ represents a variable resistor used to balance the Wheatstone bridge, $R_{1}$ is the integrated strain gauge of the MEMS device having a static value of $390 \Omega$ and $R_{G}$ represents the gain of the instrumentation amplifier. $R_{2}=R_{3}=$ $R_{4}=390 \Omega$. The supply voltage is $\pm 5 \mathrm{~V}$.

the transient behaviour; a sinusoidal waveform with a rms amplitude of $17 \mu \mathrm{N}$ at $70 \mathrm{~Hz}$ has been applied as a source. The response of the nonlinear system evinces the short oscillation condition in a single well of the potential, moving to the second one when bias exceeds the potential barrier.

Figure $8(b)$ shows the displacement of the MEMS beam using a higher frequency of vibrations $(7 \mathrm{kHz})$, in this case a low pass behaviour dominates the response, as a consequence the system remains in a stable state position (equilibrium) and it oscillates inside a single well. In general, dealing with a second-order non-autonomous nonlinear dynamical system, a large variety of different behaviours can be expected including chaos [18]. The chosen well of the bistable energy function is dictated by the initial conditions. The presented simulations demonstrate the possibility of considering not only the device vibrations but also the nonlinear behaviour of a bistable system to enhance device performances. The advantage of the nonlinear mechanism has been demonstrated by numerical analysis on a millimetre device and on a MEMS cantilever beam driven with different vibration sources including low signals in order to mimic the environment noise. In the next section an experimental campaign will be presented and the bistable mechanism applied to a micromachined device designed and realized.

\section{MEMS prototype and experimental results}

The micromachined device is a cantilever beam, realized by using a BESOI (bulk and etched silicon-on-insulator) process, realized at the Centro Nacional de Microelectronica (CNM) in Barcelona, Spain. This technology offers more robustness 


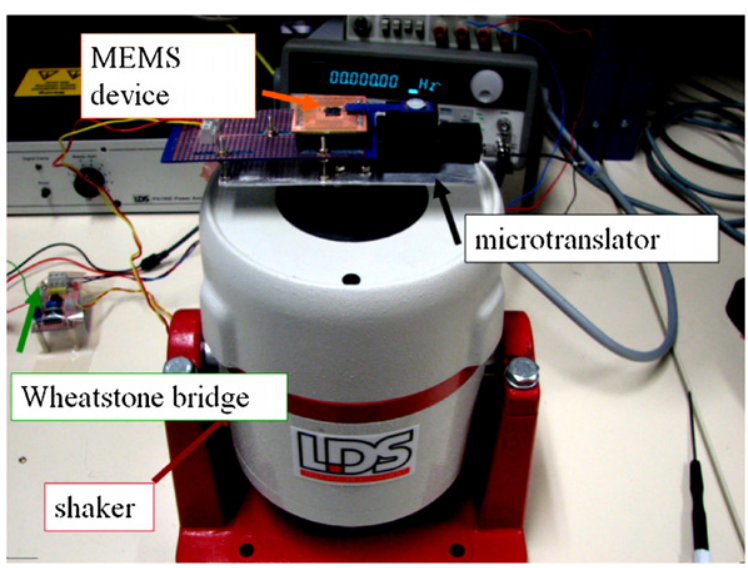

(a)

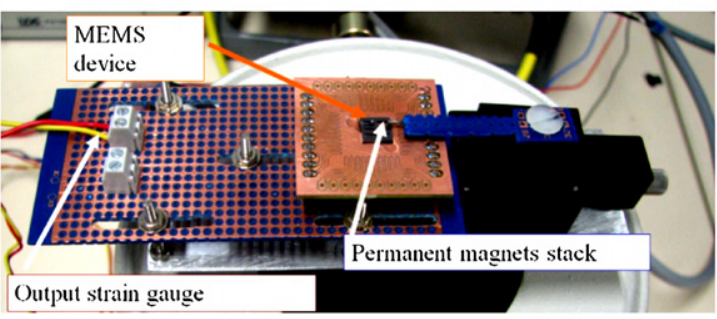

(b)

Figure 12. (a) Experimental setup for the validation of the nonlinear mechanism, $(b)$ zoom of the packaged micromachined device with the permanent magnets stack for the tuning.

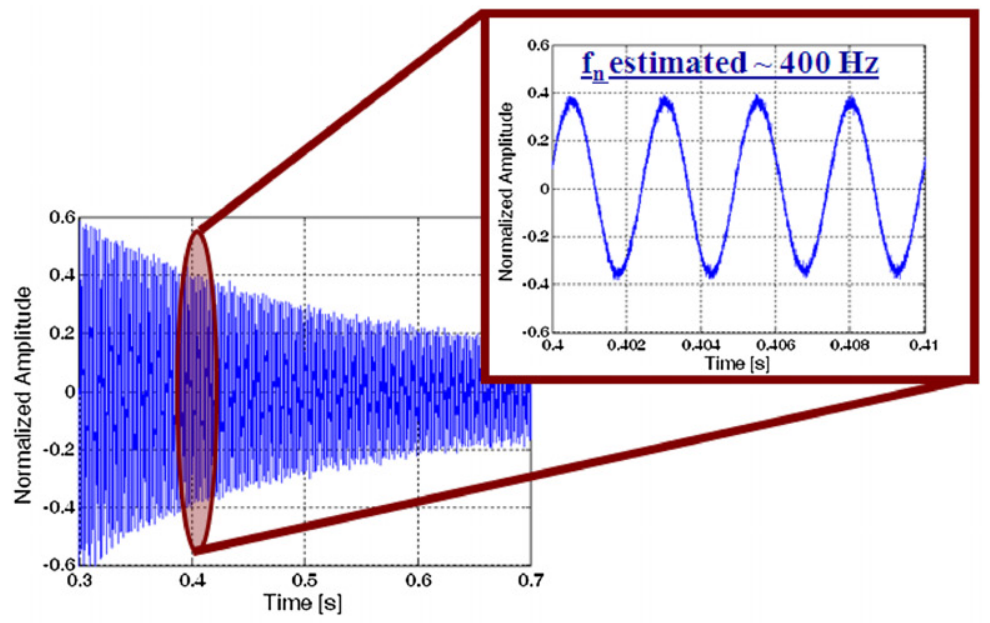

(a)

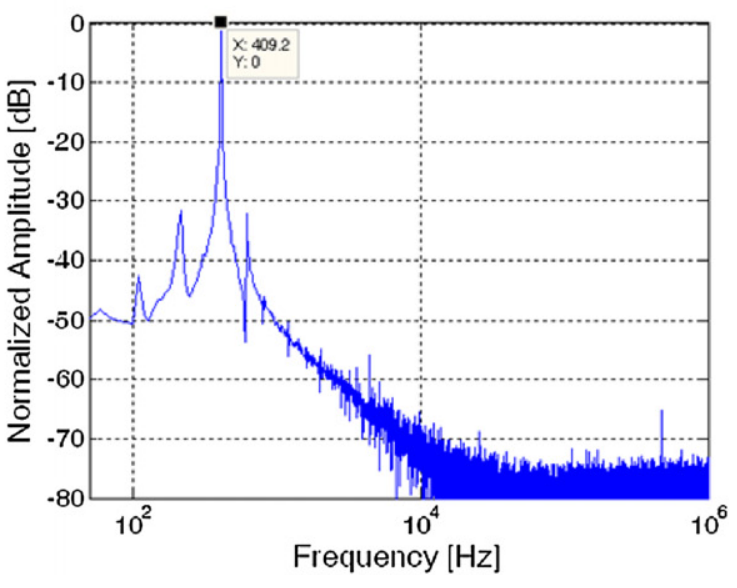

(b)

Figure 13. (a) Natural frequency of the BESOI cantilever beam having an inertial mass of $\sim 2.6 \times 10^{-6} \mathrm{~kg}$. Through the second-order model inversion, the spring constant $\left(15 \mathrm{~kg} \mathrm{~s}^{-2}\right)$ and the damping coefficient $\left(2.2 \times 10^{-4} \mathrm{~kg} \mathrm{~s}^{-1}\right)$ have been estimated, $(b)$ frequency response.

than standard processes. It is based on a SOI wafer with a $15 \mu \mathrm{m}$ c-Si layer, $450 \mu \mathrm{m}$ carrier substrate and $2 \mu \mathrm{m}$ of buried oxide; a front and backside DRIE etching technique has been used. Functional materials such as metal and polysilicon have also been added to increase the stoutness of the MEMS device as shown in figure $9(a)$. A silicon cantilever beam having a length of $2000 \mu \mathrm{m}$ and a width of $800 \mu \mathrm{m}$ has been realized. The stacked materials are composed of a $15 \mu \mathrm{m}$ thick silicon layer, several oxide layers (diff, cont, pad), a polysilicon layer and a metal layer. Figure $9(b)$ shows the layout of the device: the polysilicon layer has been used to realize the piezoresistor for the readout of the bistable mechanism; a passivation layer completes and protects the stack. Figure 10 shows the micromachined cantilever in the presence of the permanent magnet successfully deposited at the tip; the two stable states have been statically verified. The switching has been imposed through an external permanent magnet. The permanent magnet deposited consists in a cylindrical shape of $\mathrm{NdFeB}$ material having a radius and height of $500 \mu \mathrm{m}$. The distance between the fixed magnet stack (figure 10) and the tip of the beam represents the parameter $\Delta$, used as a tuning variable.

The die has been glued in a PCB package and the polysilicon strain gauge has been bonded. The conditioning circuit consists in a Wheatstone bridge followed by a lownoise amplifier, as shown in figure 11. The experimental setup (figure 12) consists of a board to support the packaged device, a micro translator for sustaining the fixed magnet stack and tuning the potential barrier. Finally, a shaker has been used as a vibration source driven by a signal generator. An accelerometer has been used as a feedback element and the output of the conditioning circuit has been connected to an acquisition system. The first analysis consists of the natural frequency estimation. The shaker has been driven by a square waveform. The evolution of the natural oscillations is shown in figure 13; a frequency of about $400 \mathrm{~Hz}$ has been detected. The value measured is in accordance with magnetic mass deposited onto the beam (500 $\mu \mathrm{m}$ of width); in fact, a 

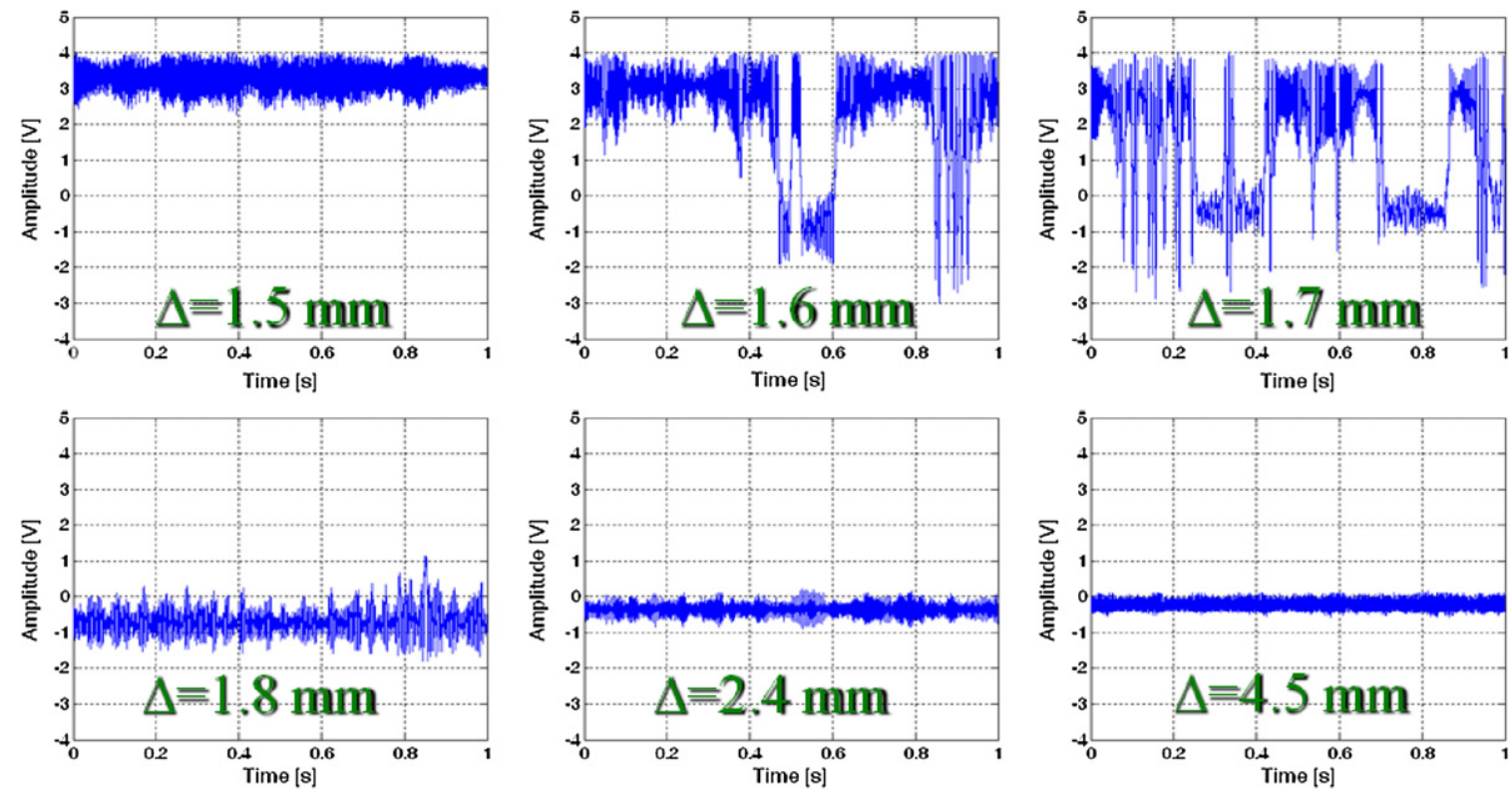

Figure 14. Output signal for different values of $\Delta$ at $\sigma=20 \mu \mathrm{N}$. The values 1.5 and $4.5 \mathrm{~mm}$ represent the lower and the upper limit of the distance between the two magnets, respectively. The lower case is imposed by the microtranslator, while the upper case represents the breaking limit of the device. The optimal condition for the nonlinear is about $1.7 \mathrm{~mm}$ of distance between the two magnetic sources. The lower limit of distance $\Delta$ is $1.4 \mathrm{~mm}$, this value in given by the breaking limit of the beam.

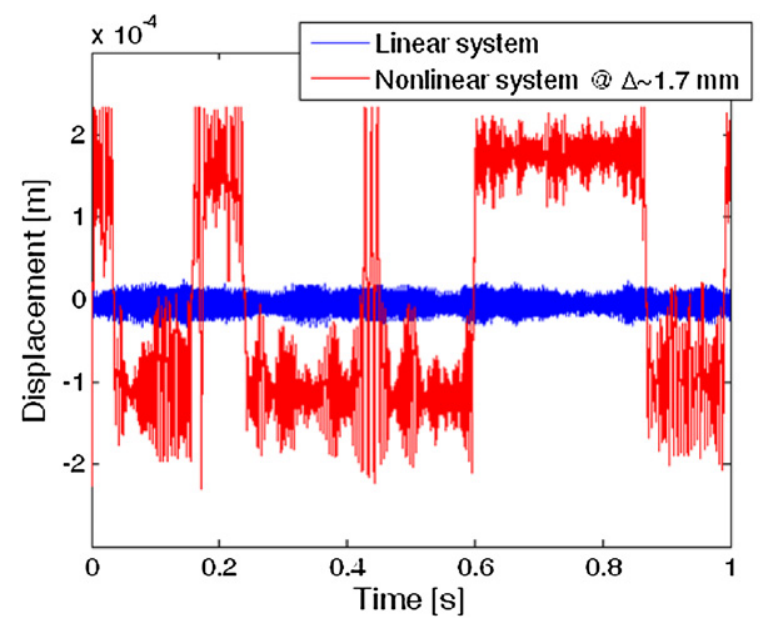

(a)

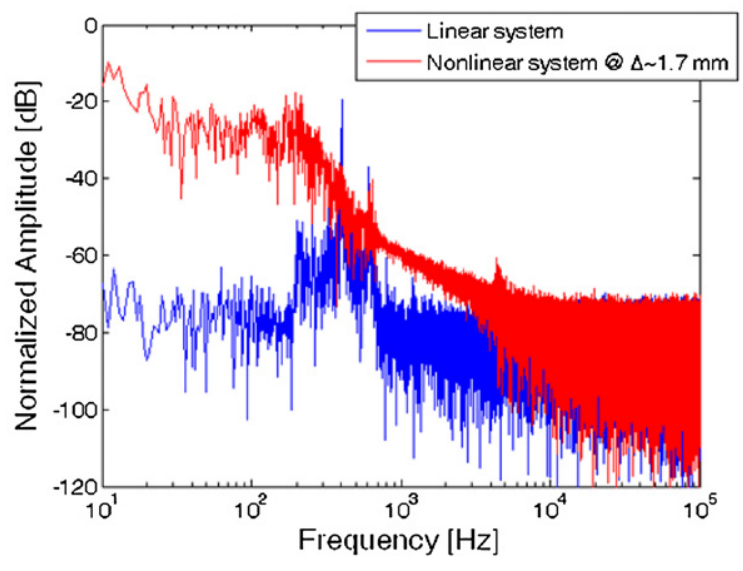

(b)

Figure 15. Experimental results: (a) displacement of the cantilever tip and (b) displacement spectrum with $\sigma=20 \mu \mathrm{N}$.

substantial mass added to the structure implies a relatively low natural frequency.

The campaign has been realized using two vibration values $(\sigma=17$ and $20 \mu \mathrm{N}$, that correspond to 6.5 and $7.7 \mathrm{~m} \mathrm{~s}^{-2}$ of acceleration, respectively). The output voltage of the conditioning circuit has been analysed; moreover, by using a displacement measurement system, the correlation between the output voltage and the displacement of the cantilever beam has been estimated. Figure 14 shows the output signal analysis for different values of $\Delta$ and a Gaussian white noise source having a standard deviation of $20 \mu \mathrm{N}$. The results are coherent with the theoretical analysis and evince the possibility of adopting a nonlinear mechanism applied to a MEMS prototype.
Basically the different graphs denote the effect of the repulsive force given by the magnets. A value of about $1.7 \mathrm{~mm}$ has been experimentally detected as the optimal condition for the nonlinear system. In fact an analysis around this value shows the single stable state in the presence of a bistability with high potential barrier $\Delta \sim 1.5 \mathrm{~mm}$, whereas high values of $\Delta$ evinces the single stable state dictated by the parabolic shape of the energy function. A condition exists where the switching mechanism between the two stable states is assumed, with a so-obtained improvement in displacement and velocity of vibration. This represents an interesting result in the perspective of energy harvesting applications. Figure 15(a) shows the evolution of the displacement, while figure 15(b) shows the displacement spectrum. Both the figures show the improvement of the nonlinear system in 


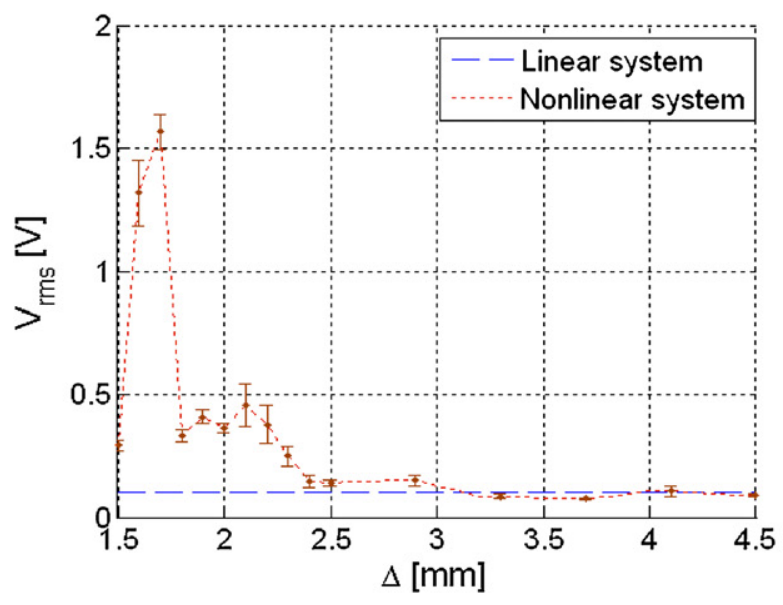

(a)

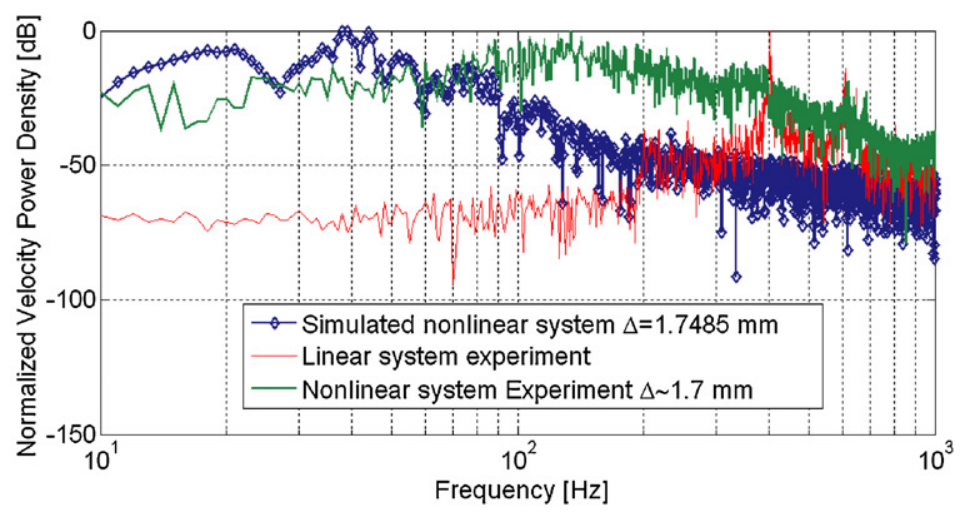

(b)

Figure 16. (a) Root mean square of the output voltage; considering the uncertainly, about 2019 commutations have been detected in $1 \mathrm{~s}$ and (b) velocity power spectral density comparison $(\sigma=20 \mu \mathrm{N})$ : the improvement (in terms of velocity PSD) for the nonlinear system is about twice compared to the classical linear oscillator (the bandwidth considered corresponds to $1 \mathrm{kHz}$ ).

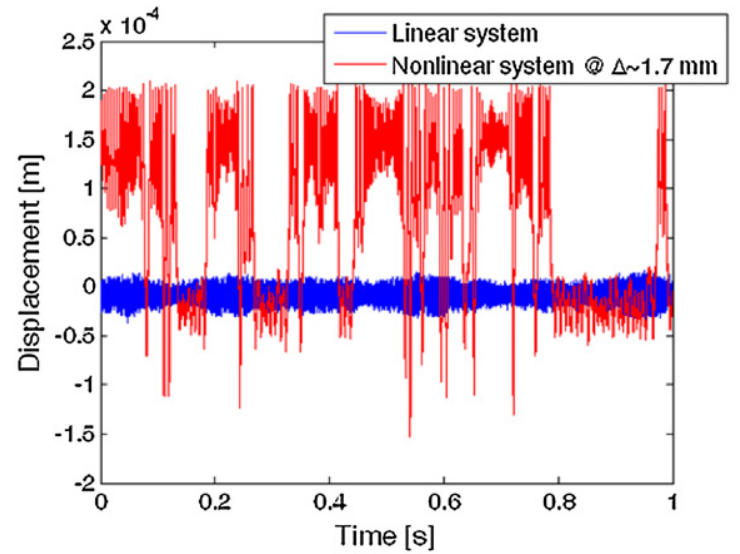

(a)

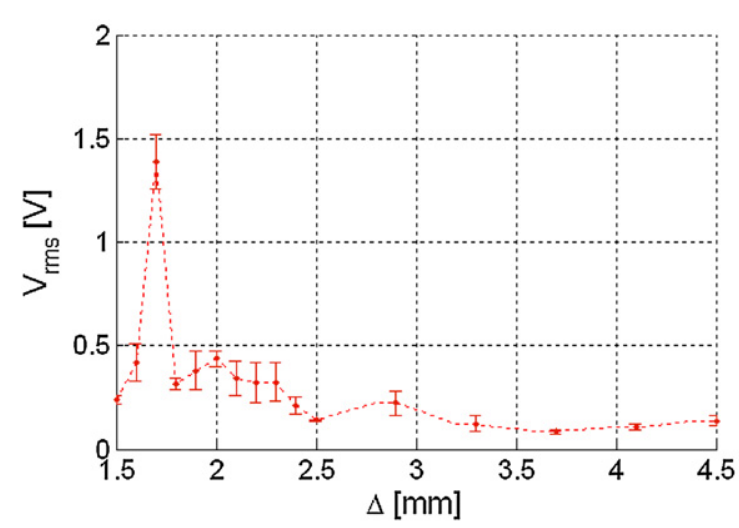

(c)

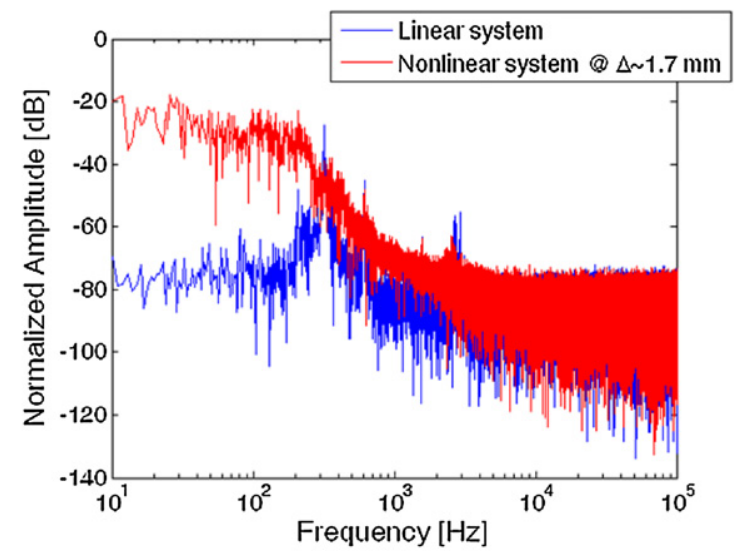

(b)

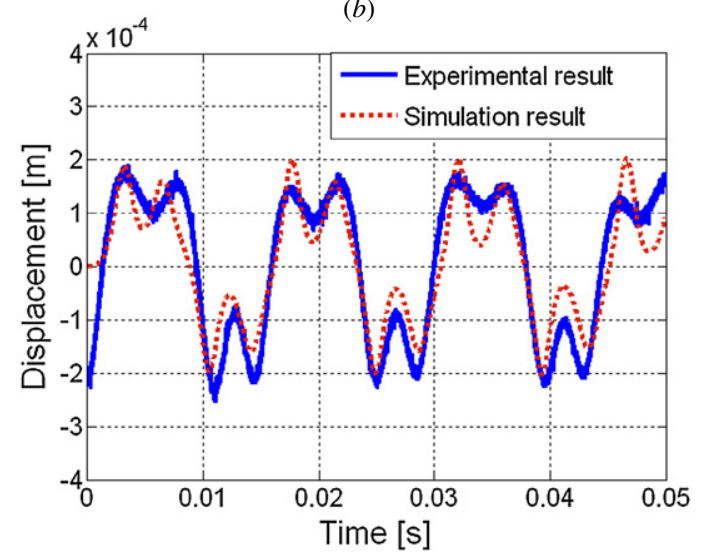

$(d)$

Figure 17. Experimental results: (a) displacement of the cantilever tip and (b) the displacement spectrum with $\sigma=17 \mu \mathrm{N}$. (c) Root mean square of the output voltage; considering the uncertainty, about 1170 commutations have been detected in 1 s. $(d)$ Single tone analysis: comparison between experimental and simulation results for the same beam's parameters; a sinusoidal bias at $70 \mathrm{~Hz}$ has been used as suprathreshold force $(\sigma=17 \mu \mathrm{N})$.

terms of displacement and spectrum that appear wider with respect to the linear case as a consequence of the nonlinear dynamic.

Figure 16 shows the output voltage as a function of the distance between the two magnets. The nonlinear system has been compared with the linear system (without the permanent magnets stack). The results are in agreement with the theory and the nonlinear system tends asymptotically to the linear system in the presence of a high value of $\Delta$. Furthermore, the power spectrum density appears wider compared to the 
Table 1. Comparison of this paper with other published works.

\begin{tabular}{|c|c|c|c|c|c|c|c|}
\hline $\begin{array}{l}\text { Piezoelectric } \\
\text { thickness }(\mu \mathrm{m})\end{array}$ & $\begin{array}{l}\text { Total geometric } \\
\text { characteristics }(\mathrm{mm})\end{array}$ & $\begin{array}{l}\text { Vibration } \\
\text { characteristic }(\mathrm{Hz})\end{array}$ & $\begin{array}{l}\text { Output } \\
\text { power }(\mu \mathrm{W})\end{array}$ & $\begin{array}{l}\text { Amplitude of } \\
\text { acceleration }(\mathrm{g})\end{array}$ & $\begin{array}{l}\text { Improvement } \\
\text { factor }\end{array}$ & $\begin{array}{l}\text { MEMS } \\
\text { technology }\end{array}$ & Reference \\
\hline 2 & $0.80 \times 1.2$ & 870 & 1.4 & 2 & - & Yes & [37] \\
\hline 0.48 & $0.26 \times 0.17$ & $13.9 \mathrm{k}$ & 1 & 10.8 & - & Yes & [38] \\
\hline 267 & $17 \times 5$ & 100 & 80 & 0.23 & - & No & [39] \\
\hline$\sim 50$ & $23 \times 20$ & 80 & 2 & 23 & - & No & [40] \\
\hline 250 & $10 \times 40$ & 120 & 500 & 0.1 & - & No & [41] \\
\hline 860 & $60 \times 5$ & $\begin{array}{l}\text { Correlated noise } \\
1 / \tau=1 / 0.1\end{array}$ & 3.2 (nonlinear) & 0.0079 & $400 \%$ & No & [21] \\
\hline 400 & $\sim 60$ & $20-100$ & $\begin{aligned} & 0.8 \text { (linear) } \\
\sim & 28 \mathrm{k} \text { (nonlinear) } \\
\sim & 22 \mathrm{k} \text { (linear) }\end{aligned}$ & 4 & $130 \%$ & No & {$[42]$} \\
\hline - & $2 \times 0.8$ & Gaussian white noise & - & 0.78 & $200 \%$ & Yes & This work \\
\hline
\end{tabular}

linear case; consequently, it is possible to save more energy by using the nonlinear MEMS mechanism. Figure 17 shows the experimental results in the case of $\sigma=17 \mu \mathrm{N}$. Table 1 presents a comparison of this paper (last row) with other published works. In particular the last three rows concern nonlinear devices. It must be observed that the proposed MEMS oscillator presents an improvement factor of $200 \%$; it has been evaluated integrating the velocity power density over a bandwidth of $1 \mathrm{kHz}$ in the linear and the nonlinear cases. It appears for the same input acceleration that the nonlinear device collects two times more power with respect to the linear case. It is worth noting that this improvement factor of 2 depends on the input noise characteristics. With a smaller input bandwidth the improvement will increase because the power will be at lower frequency than the resonance.

\section{Conclusions}

In this paper, a nonlinear bistable mechanism, implemented through a modified MEMS cantilever, has been presented. The bistable device presented here is intended to be used in energy harvesting systems to scavenge energy from mechanical vibrations in the environment. The principle demonstrated an enhancement of the performance, with respect to linear harmonic oscillators for a nonlinear oscillator, when the response to external vibrations is considered. This is interesting in the perspective of integrated energy harvesting systems.

In fact, conventional energy harvesting approaches are based on linear resonators with a transduction energy system (e.g. piezoelectric output) for collecting energy. However, it must be observed that in the vast majority of cases the ambient vibrations assume different forms and are characterized by energy distributed over a wide spectrum of frequencies. Hence the linear system, characterized by a resonance spike, around the natural mechanical frequency, does not represent the most appropriate approach to collect the energy.

The presented approach is based on a nonlinear dynamical system whose particularity consists of bouncing between two stable states as a response to external solicitations. This type of system has a dynamic response to a wide spectrum signal which is interesting to collect energy from external vibrations. A numerical analysis has been realized by implementing a second-order equation with an additive nonlinear and bistable term; moreover, a noise source has been used as an excitation bias. The stochastic model has been simulated starting from a millimetre beam and finally to a micrometric device.

An improvement in terms of collected energy has been demonstrated for both systems and bistable behaviour has been verified. Therefore, a micromachined BESOI device has been designed and realized. A measurement campaign has been conducted by using a micromachined cantilever with a magnetic material successfully deposited on the tip.

The obtained experimental results confirmed the achievement of the nonlinear bistable behaviour principle applied to a MEMS device, moreover, it has been demonstrated (in accordance with the simulation results) as the achievement of a significant improvement in terms of conversion of kinetic energy form the external wideband vibrations when compared to a linear resonant device. These results represent a major advance with respect to the state-of-the-art in the energy harvesting area; in fact the device that has been designed, realized and validated in this work can be highly efficient for scavenging energy from a large range of vibration sources with different natures and therefore different spectral contents. The advantage of the nonlinear mechanism has been validated using the testing data obtained through the piezoresistive transduction mechanism. Moreover, a measurement campaign for a sol-gel PZT-based device and its modelling will be conducted.

\section{References}

[1] Raghunathan V, Kansal A, Hsu J, Friedman J and Srivastava M 2005 Design considerations for solar energy harvesting wireless embedded systems IEEE Int. Symp. on Information Processing in Sensor Network (IPSN) (Los Angeles, CA, 25-27 April)

[2] Sodano H A, Inman D J and Park G 2005 Comparison of piezoelectric energy harvesting devices for recharging batteries J. Intell. Mater. Syst. Struct. 16 799-807

[3] Torah R, Jones P G, Tudor M, O'Donnell T, Roy S and Beeby S 2008 Self-powered autonomous wireless sensor node using vibration energy harvesting Meas. Sci. Technol. 19125202

[4] Anton S R and Inman D J 2008 Energy harvesting for unmanned aerial vehicles Proc. SPIE 6928692824

[5] Kuo A D 2005 Harvesting energy by improving the economy of human walking Science 309 1686-7 
[6] Guyomar D, Jayet Y, Petit L, Lefeuvre E, Monnier T, Richard C and Lallart M 2007 Synchronized switch harvesting applied to self-powered smart systems: piezoactive microgenerators for autonomous wireless transmitters Sensors Actuators A 138 151-160

[7] Roundy S, Wright P K and Rabaey J M 2003 Energy Scavenging for Wireless Sensor Networks with Special Focus on Vibrations (Dordrecht: Kluwer Academic)

[8] Challa V R, Prasad M G, Shi Y and Fisher F T 2008 A vibration energy harvesting device with bidirectional resonance frequency tenability Smart Mater. Struct. 17015035

[9] Peters C, Maurath D, Schock W and Manoli Y 2008 Novel electrically tunable mechanical resonator for energy harvesting Proc. PowerMEMS 2008 (Sendai, Japan, 9-12 November) pp 253-6

[10] Ferrari M, Ferrari V, Guizzetti M, Marioli D and Taroni A 2008 Piezoelectric multifrequency energy converter for power harvesting in autonomous microsystems Sensors Actuators A 142 329-35

[11] Sari I, Balkan T and Kulah H 2007 A wideband electromagnetic micro power generator for wireless microsystems Proc. Transducers 2007 (Lyon, France, 10-14 June) pp 275-8

[12] Mann B P and Sims N D 2009 Energy harvesting from the nonlinear oscillations of magnetic levitation J. Sound Vib. $319515-30$

[13] Lee D G, Carman G P, Murphy D and Schulenburg C 2007 Novel micro vibration energy harvesting device using frequency up conversion Proc. Transducers 2007 (Lyon, France, 10-14 June) pp 871-4

[14] Chung T K, Lee D G, Ujihara M and Carman G P 2007 Design, simulation, and fabrication of a novel vibration-based magnetic energy harvesting device Proc. Transducers 2007 (Lyon, France, 10-14 June) pp 867-70

[15] Carlioz L, Delamare J and Basrour S 2009 Temperature threshold tuning of a thermal harvesting switch Proc. Transducers 2009 (Denver, CO, 21-25 June) pp 1385-8

[16] McInnes C R, Gorman D G and Cartmell M P 2008 Enhanced vibrational energy harvesting using nonlinear stochastic resonance J. Sound Vib. 318 655-62

[17] Stanton S C, McGehee C C and Mann B P 2010 Nonlinear dynamics for broadband energy harvesting: investigation of a bistable piezoelectric inertial generator Physica D 239 640-53

[18] Hilborn R C 2000 Chaos and Nonlinear Dynamics: An Introduction for Scientists and Engineers 2nd edn (Oxford: Oxford University Press)

[19] Mann B P and Owens B A 2010 Investigations of a nonlinear energy harvester with a bistable potential well J. Sound Vib. 329 1215-26

[20] Wang D, Pham H and Hsieh Y 2009 Dynamical switching of an electromagnetically driven compliant bistable mechanism Sensors Actuators A 149 143-51

[21] Cottone F, Vocca H and Gammaitoni L 2009 Nonlinear energy harvesting Phys. Rev. Lett. 102080601

[22] Ferrari M, Ferrari V, Guizzetti M, Andò B, Baglio S and Trigona C 2009 Improved energy harvesting from wideband vibrations by nonlinear piezoelectric converters Proc. Eurosensors XXIII (Lausanne, Switzerland, 6-9 September 2009) pp 1203-6
[23] Ferrari M, Ferrari V, Guizzetti M, Andò B, Baglio S and Trigona $C 2010$ Improved energy harvesting from wideband vibrationsby nonlinear piezoelectric converters Sensors Actuators A 162 425-31

[24] Andò B, Baglio S, Dumas N, Latorre L, Nouet P and Trigona C 2010 Nonlinear behaviour of a micromachined SOI device for energy harvesting application Proc. DTIP (Seville, Spain 5-7 May 2010) pp 263-5

[25] Wellen T, Shatokhin V and Buchleitner A 2004 Stochastic resonance Rep. Prog. Phys. 67 45-105

[26] Qiu J, Lang J H and Slocum A H 2004 A curved-beam bistable mechanism J. Microelectromech. Syst. 13 137-46

[27] Casal-Terre J and Shkel A 2005 Snap-Action bistable micromechanism actuated by nonlinear resonance Proc. IEEE Sensors Conf. (Irvine, CA, 31 Oct.-3 Nov.)

[28] Boyle P, Moore D F, Breen R, Syms R A, Zou H and Stagg J 2004 MEMS bistable clamp with electrical locking and release 15th Micromechanics Workshop MME '04 (Leuven, Belgium, 5-7 September)

[29] Harmer G P, Davis B R and Abbott D 2002 Review of stochastic resonance: circuits and measurement IEEE Trans. Instrum. Meas. 51 299-309

[30] Bulsara A R and Gammaitoni L 1996 Tuning in to noise Phys. Today 49 39-45

[31] Gammaitoni L and Bulsara A R 2002 Phys. Rev. Lett. 88230601

[32] Andò B, Baglio S, Bulsara A R and Trigona C 2009 Design and characterization of a microwire fluxgate magnetometer Sensors Actuators A 151 145-153

[33] Kloeden P E and Platen E 1999 Numerical Solution of Stochastic Differential Equations (Berlin: Springer)

[34] Picchini U SDE Toolbox: Simulation and Estimation of Stochastic Differential Equations with Matlab http://sdetoolbox.sourceforge.net

[35] Higham D J, Mao X and Stuart A M 2003 Strong convergence of Euler-type methods for nonlinear stochastic differential equations SIAM J. Numer. Anal. 40 1041-63

[36] Jaswal H 2007 Analysis of micro-vibration in buildings Proc. 2007 Earthquake Engineering Symp. for Young Researchers (Seattle, WA, 8-12 August)

[37] Muralt P, Marzencki M, Belgacem B, Calame F and Basrour S 2009 Vibration energy harvesting with PZT micro device Proc. Chem. 1 1191-4

[38] Jeon Y B, Sood R, Jeong J H and Kim S G 2005 MEMS power generator with transverse mode thin film PZT Sensors Actuators A 122 16-22

[39] Roundy S, Wright K P and Rabaey J 2003 A study of low level vibrations as a power source for wireless sensor nodes Comput. Commun. 26 1131-44

[40] White N M, Glynne-Jones P and Beeby S P 2001 A novel thick-film piezoelectric micro-generator Smart Mater. Struct. 10 850-2

[41] Jeonga S J, Kima M S, Songa J S and Leeb H 2008 Two-layered piezoelectric bender device for micro-power generator Sensors Actuators A 148 158-67

[42] Baker J, Roundy S P and Wright P 2005 Alternative geometries for increasing power density in vibration energy scavenging for wireless sensor networks Proc. 3 rd Int. Energy Conversion Engineering Conf. (San Francisco, CA, 15-18 August) pp 1-12 